\title{
Identifying the cause of cutting tool failure by using simulation software
}

\author{
Andrej Zrak ${ }^{1, *}$, Radoslav Koňár ${ }^{1}$ \\ ${ }^{1}$ Univeristy of Žilina, Faculty of Mechanical Engineering, Univerzitná 1, 010 26, Žilina
}

\begin{abstract}
The article is focused on the construction problems of cutting tools designed for manufacturing components in high numbers. Analysis of the tool with low lifetime is provided with the use of simulation software to detect the causes of the tool failure. Parameters of the simulation are close to the real conditions of the tool in production. The results from the simulation indicate that the bending moment occurs in the tool because of forces which have opposite direction on different areas. On these basis technological adjustments are made. These adjustments are also analysed by using simulation software.
\end{abstract}

Keywords: cutting tool, stress analysis, failure of cutting tool, position of energy force

\section{Introduction}

Forming technology is mostly applied in manufacturing parts that are made in high quantity. The reason for applying this technology is its low time consumption. The manufacturing process takes only few seconds. On the other hand, when producing low quantities, forming technology is not effective because of the high costs when manufacturing the forming tool or tools.

From the point of manufacturing and renovation costs of the forming tools, its lifetime in production environment is essential. This article describes the analyses of the tool, which was designed for progressive forming of components. The number of manufactured parts without the need to repair the tool was very low (sometimes 200 pcs. and the assumed number when designing the tool was approximately 5000 pcs.)

\section{Analysis of the cutting tool}

The object used for analyses is called progressive forming tool which is used for cutting components from steel S235 JR (thickness $t=4 \mathrm{~mm}$ ). This tool was examined (Fig. 1) because of its low lifetime during production. The functional parts of the tool are made out of tool steel $50 \mathrm{CrMoV} 1314$, heat treated to $62 \mathrm{HRC}$. Fixing parts of the tool are made from steel E355. In one cutting cycle the tool cuts two identical parts for better effective use of the material.

\footnotetext{
*Corresponding author: andrejzrak@gmail.com

Reviewers: Piotr Krawiec, Tadeusz Zloto
} 




a)

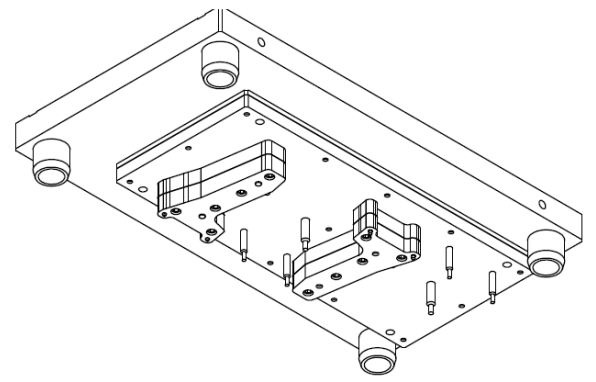

b)

Fig. 1. Analysed cutting tool. a) bottom part, b) upper part

Design of the tool is characterized by the different high of the punches. Half of the punches are about $4 \mathrm{~mm}$ higher (thickness of the steel sheet). This means that the cutting process proceeds in two phases. At first the material is cut by the left side of the punches and then by the right. Fig. 2 describes the differences of maximal cutting force when cutting by using all punches at the same time (Fmax1), and when cutting by using different high of the punches (Fmax). At different heights the cutting force is not so high and the dynamic strain on the machine and tool is lower. Cutting energy (integrated area under the cutting force curve) is for cutting with the identical height of the punches theoretically equal to the total of cutting energy for classes of punchers with the same height $[8,10,11]$.

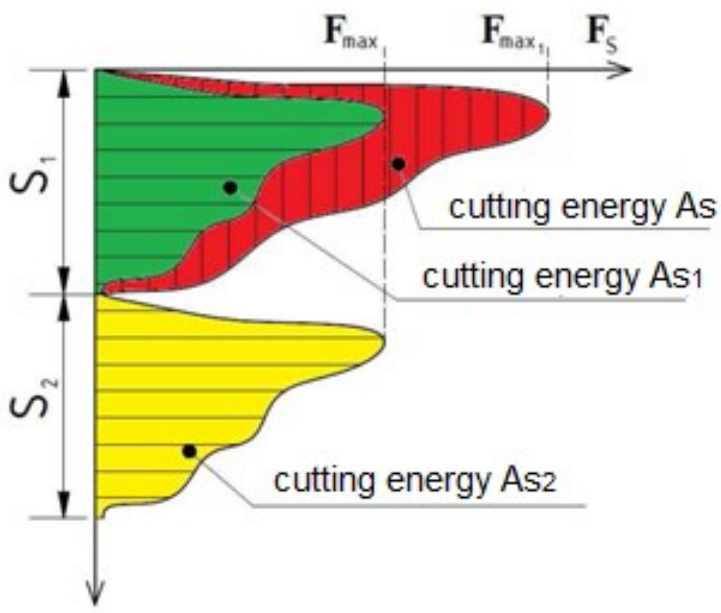

Fig. 2. Description of cutting force

Simulation of the authentic tool was carried out in Autodesk Inventor Professional software. This simulation corresponds to the realistic conditions in praxis. The force effect initiated by the press machine was located on the upper plate of the tool. Force from the press was $1300 \mathrm{kN}$ for one set of punchers. This force replacement is sufficient enough, because the machine which affects the tool by force is not enough precise and stiff to ensure force effects to prevent the plate from moving in the plane direction perpendicular to the vector of force action. 
Free movement in the plane which is perpendicular to the vector of force action was verified by using camera system. The magnitude of force effect was estimated on the basis of theoretical calculation of cutting force for selected tool. Measuring of realistic force effect was not provided for the lack of strain gauges containing necessary measuring scale to detect the force effect $(2600 \mathrm{kN})$. Fig. 3 describes the output of simulation focused on the size of movements from each parts of the tool during cutting by the first assembly of punchers with bigger length $[2,5,7,9]$.

According to the analysis of the model it is possible to assume, that the force effect from the machine on the tool causes a bending moment. This moment is responsible for radial fatigue of the guiding elements and causes deviation of the upper part of the tool due to the lower part.

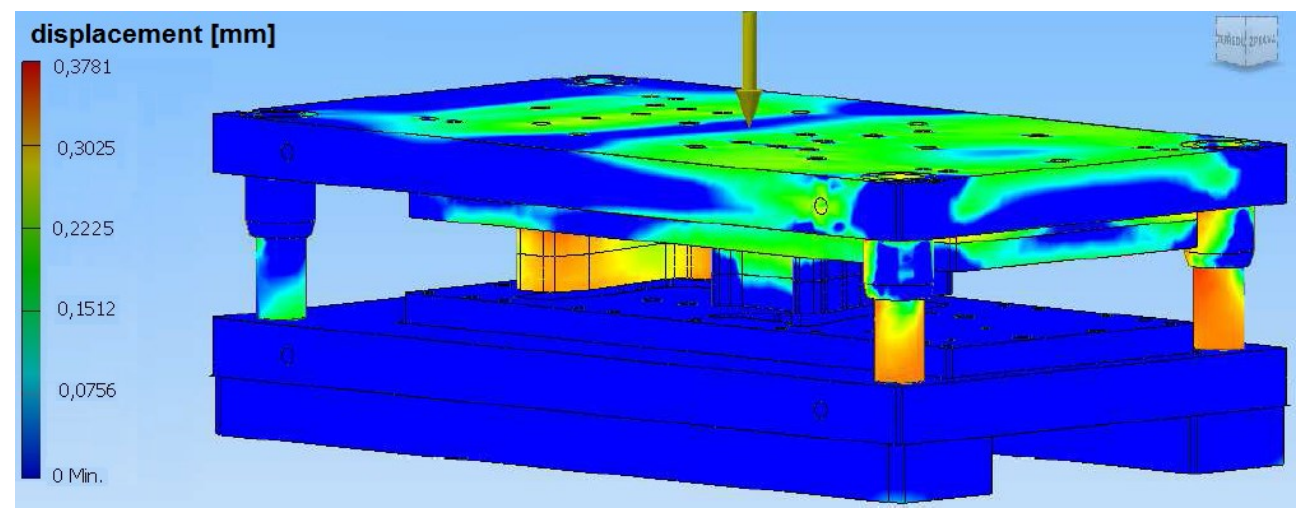

Fig. 3. The magnitude of each part movement of the tool during cutting by using the first half of the punches

Fig. 4 describes the model of cutting with displayed clearance. Clearance is a parameter related to the properties and thickness of the cut material. In this case the applied clearance has a value of $0.2 \mathrm{~mm}$. If we take into considering that the functional parts of the tool move in the process of cutting $0.2 \mathrm{~mm}$ from each other, their misalignment is from 0.2 to $0.3 \mathrm{~mm}$. The result is that the clearance is reduced to zero value on one side and doubled on the other side of the puncher. In worst case scenario the two punchers collide. This can be also observed from the result of simulation. Collision of punchers with hardness 62 HRC causes the abruption of cutting edge and the tool is then not sharp (one of the causes of tool damage from service data). Continuing wear process of the tool increases exponentially. Wear o the tool is excessive also in the case that the clearance is not optimal. By using simulation technologies there can be a chance to predict the state of zero clearance and to avoid the negative influence on the tools lifetime. Wrong clearance has also negative influence on the quality of the steel blanks. Analysis of the blanks which have been cut by using this tool had proved this assumption.

Result from the simulation (Fig. 3) represents the state during cutting by using the right set of punchers. After cutting this part the left side of the set cuts the rest. The strain of guiding elements is equal with opposite vector of orientation. From determined facts it is possible to state that the upper part of the tool during one cycle moves approximately 0.2 $0.3 \mathrm{~mm}$ to the right side and then $0.4-0.6 \mathrm{~mm}$ to the left. This movement causes high wear of the guiding elements and increases the size of shifting in the next cycles $[4,6,9]$. 


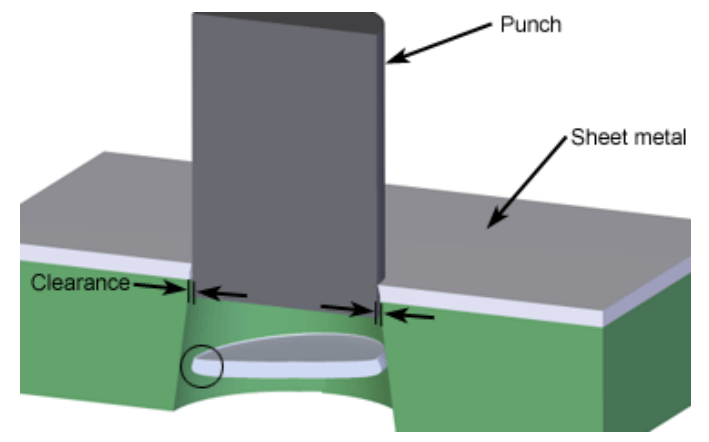

Fig. 4. Cutting scheme - clearance [1]

\section{Proposition of steps leading to the increase of cutting tool lifetime}

On the basis of determined facts two steps of increasing the lifetime of the cutting tool were proposed.

\subsection{Cutting with the same height of the punchers}

Main disadvantage, when cutting where the punchers have identical height, is that there is a need to apply bigger forces on the tool to make the cut. This force effect changes its character non-uniformly and creates shock stress of the tool. Its advantage is that the puncher does not initiate bending moment, which influences the tool because the force effect of the machine and the counter effect of the table is in one axis. Fig. 5 represents the result of simulation focused on the movement of tool parts during cutting with the same height of the punchers at two times bigger load $(2600 \mathrm{kN})[5,7,9]$.

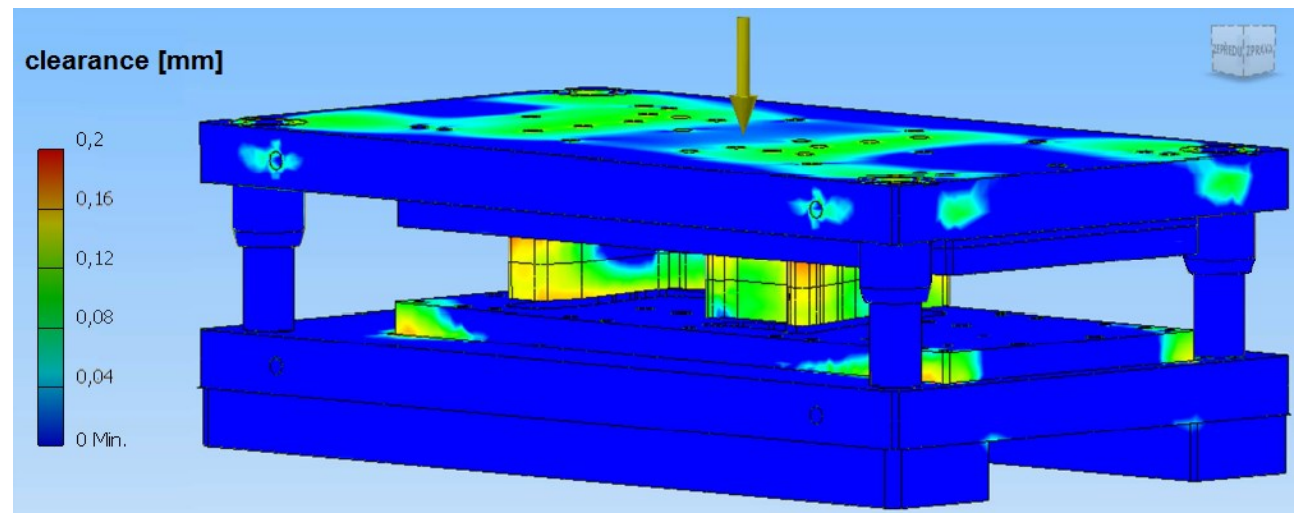

Fig. 5. Result from the simulation of cutting with same height of the punchers

Simulation proves the assumption that this way of cutting does not initiate force effect in the guiding elements of the tool and does not cause the misalignment of punchers from the designed motion trajectory. From detail analysis of the most strained parts, none of the areas reach the yielding strain of the material. That means the designed method is safe, preventing the tool to be damaged. Of course by using this method there is a need for a press, which can produce a force load minimally $30000 \mathrm{kN}$ for the tool. 


\subsection{Cutting with identical height of the punchers including angle change of the edge}

Origin conception of the tool was manufactured by using the most common used method for decreasing the maximal cutting force. By using this method, it is very important to insure, that the resultant force effect is always in the middle of the force effect of the used press. In this case, from the conception of the used press, it is not possible to reach this method. That means there had to be proposed another solution $[2,5,7]$.

Next way how to decrease the maximal cutting force and to secure the resultant force effect in the middle is to grind the punchers under defined angle (Fig. 6). This modification of punchers causes the cut to be executed sequentially, the force effect is not on the $4 \mathrm{~mm}$ path (thickness of the material) but on $8 \mathrm{~mm}$ path. If we take into consider that the cutting energy stays approximately the same (increased by the energy, which is consumed for the deformation of the cut material), it can be possible to state that, at tools which have symmetrical geometry, the maximal cutting force in this case is approximately half of the original. Disadvantage of the proposed method of cutting is that the blank does not have planar character, but is slightly deformed to a cylinder shape. Therefore it is necessary to include a straightening operation.

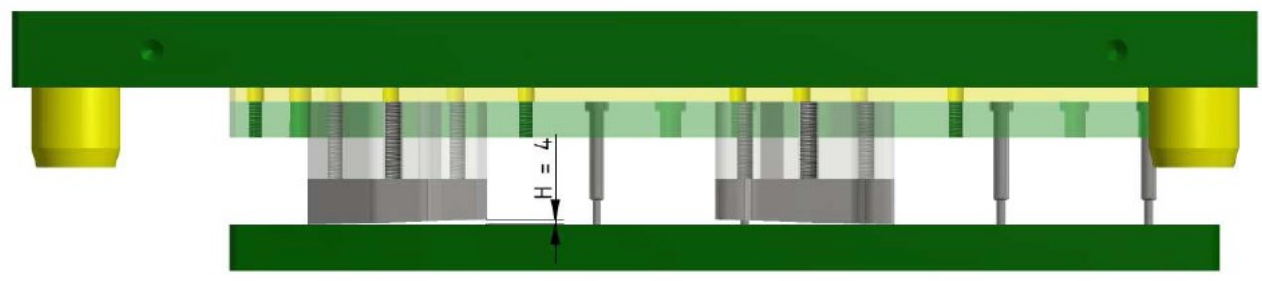

Fig. 6. Angle grinding of the punchers

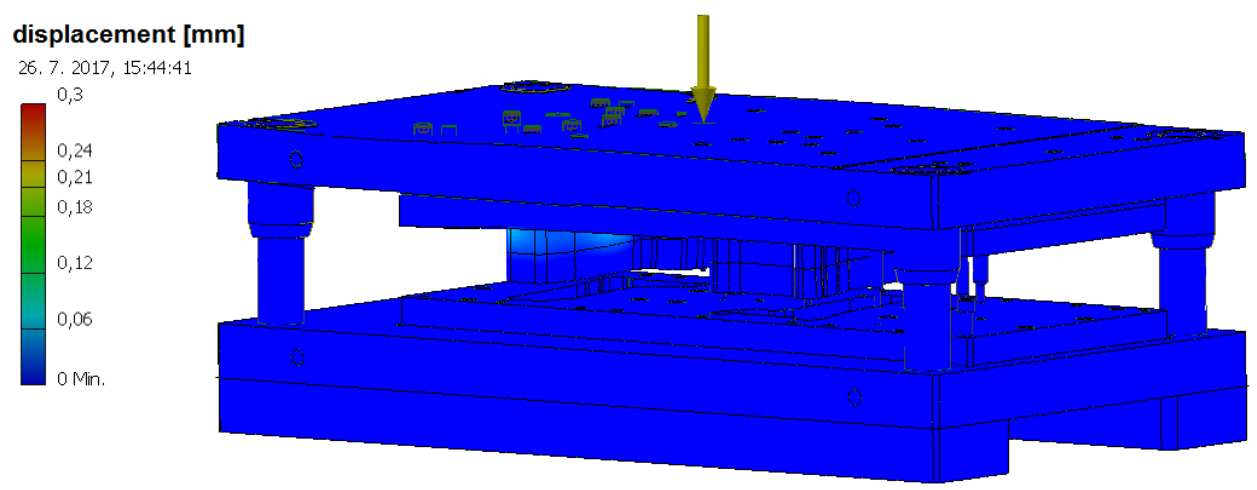

Fig. 7. Result from the simulation of punchers that were grinded under defined angle

From the analysis it is possible to state that the designed conception does not initiate movement in the radial direction on the force vector of the press(fig. 7). Here can be seen that the stated modification of the puncher induces small radial stress. This stress is caused because of the leaning cutting surface. At dimensions of this puncher the subscribed method does not negatively influence the operation of the tool and does not cause damage or abnormal misalignment. 


\section{Conclusion}

The article contains analysis of a tool which is used in technical praxis to manufacture parts by using progressive cutting. The reason for analysis of this tool was that its lifetime was too short. According to the simulation the tool was designed in a way that during cutting the press machine acts on the tool by force which induces bending moment and this moment causes radial strain on the guiding elements. The tool in its origin conception would be possible to apply on a press which would contain movable parts with high stiffness and accuracy. The next option would be to change the guiding elements of the tool for stronger. However, from calculation of this option the size of guiding elements exceeded the dimensions that would be suitable for mounting to the tool. For effective fixture of this issue two changes of the design of the tool were proposed, without dramatic modification of the whole construction.

First method was to cut the openings synchronously where the radial strain of the guiding elements of the tool would be eliminated. On the other hand, the cutting force would be doubled. By using this method there is a need to use a press machine with higher force load.

Unfavourable is also the shock strain applied on the tool and machine. The second method is that the surface of the punchers would be grinned in a defined angle and would cut synchronously. Forming punchers with big dimensions can't cut on a $4 \mathrm{~mm}$ path (thickness of the material) but on an $8 \mathrm{~mm}$ path. This method decreases the maximal cutting force and does not cause radial strain of the guiding elements of the tool. The disadvantage of this method is that the blanks are deformed and therefore it is necessary to straighten them.

This article points out the importance of applying numerical simulations into designing forming tools before their manufacture. It is necessary to remark that simulations which were used to analyse the tool contained in this article are only basic analysis focused on strength and movement of the tool. However, these analyses provide important information about detecting the causes and prevention of failure or damage of the tool before putting into production.

This article was created with the support of project KEGA - 034ZU-4/2015.

\section{References}

1. Custom PartNet. [online] http://www.custompartnet.com (2009)

2. M. Žmindák, J. Meško, Z. Pelagić, A. Zrak, Finite element analysis of crack growth in pipelines. Manufacturing technology: Journal for science, research and production 14 (1), 116-122 (2014)

3. P. Novák, J. Meško, M. Žmindák, Finite element implementation of multi-pass fillet weld with phase changes. Manufacturing technology : journal for science, research and production 13 (1), 79-85 (2013)

4. M. Brezničan, P. Fabian, J. Meško, M. Drbúl, The simulation of influence of quenching temperature on properties of bearing rings. Manufacturing technology: journal for science, research and production 13 (1), 20-25 (2013)

5. R. Koňár, M. Mičian, M. Patek, D. Kadáś, Finite element modeling and numerical simulation of welding at the repair of gas pipelines with steel sleeve. Manufacturing Technology: journal for science, research and production 16 (2), 360-365 (2016)

6. J. Moravec, Increase of the operating life of active parts of cold-moulding tools. Technički vjesnik = Technical gazette 24 (1), 143-146 (2017) 
7. S. Rózowicz, S. Tofil, A. Zrak, An analysis of the microstructure, acrostructure and microhardness of NiCr-Ir joints produced by laser welding with and without preheat. Archives of metallurgy and materials 61 (2b), 1157-1162 (2016)

8. M. Patek, M. Mičian, A. Sládek, D. Kadáš, Numerical analysis of T-joint Welding with different welding sequences. Manufacturing Technology: journal for science, research and production 16 (1), 234-238 (2016)

9. M. Handrik, P. Kopas, V. Baniari, M. Vaško, M. Sága, Analysis of stress and strain of fatigue specimens localised in the cross-sectional area of the gauge section testing on bi-axial fatigue machine loaded in the high-cycle fatigue region. Procedia Engineering 177, 516-519 (2017)

10. P. Jankejech, P. Fabian, J. Bronček, Y. Shalapko, Influence of tempering on mechanical properties of induction bents below $540^{\circ} \mathrm{C}$. Acta Mechanica et Automatica 10 (2), 81-86 (2016)

11. E. Krivoš, R. Pastirčák, R. Madaj, Effect of technological parameters on the quality and dimensional accuracy of castings manufactured by patternless process technology. Archives of metallurgy and materials 59 (3), 1069-1072 (2014) 